\title{
Clinical course and medical management of neonates with severe cardiac failure related to vein of Galen malformation
}

\author{
G P Frawley, P A Dargaville, P J Mitchell, B M Tress, P Loughnan
}

See end of article for authors' affiliations

.....................

Correspondence to: Dr Frawley, Department of Anaesthesia, Royal Children's Hospital Parkville, Victoria 3052, NSW, Australia;

frawleyg@cryptic.rch. unimelb.edu.au

Accepted

29 January 2002
Arch Dis Child Fetal Neonatal Ed 2002;87:F144-F149

Background: Neonatal presentation of vein of Galen aneurysmal malformations (VGAMs) with intractable cardiac failure is considered a poor prognostic sign. Interventional neuroradiology with embolisation has been shown to control cardiac failure, but there is a perception that neurological outcome in survivors is poor.

Objective: To determine if aggressive intensive care and anaesthetic management of cardiac failure before urgent embolisation can influence morbidity and mortality.

Patients: Nine newborns (four boys, five girls) were diagnosed with symptomatic vein of Galen malformations in the neonatal period during the period 1996-2001. Eight developed intractable high output cardiac failure requiring initial endovascular treatment in the first week of life.

Results: The immediate outcome after a series of endovascular procedures was control of cardiac failure and normal neurological function in six $(66 \%)$ patients, one death from intractable cardiac failure in the neonatal period, and two late deaths with severe hypoxic-ischaemic neurological injury $133 \%$ mortality). Clinical review at 6 months to 4 years of age showed five infants with no evidence of neurological abnormality or cardiac failure and one child with mild developmental delay (11\%).

Conclusions: Aggressive medical treatment of cardiac failure and early neurointervention combined with modern neuroanaesthetic care results in good survival rates with low morbidity even in cases of high risk VGAM presenting in the immediate perinatal period with cardiac failure. Systemic arterial vasodilators improve outcome in neonates with cardiac failure secondary to VGAM. Excessive $\beta$ adrenergic stimulation induced by conventional inotropic agents may exacerbate systemic hypoperfusion.
$\mathrm{V}$ ein of Galen aneurysmal malformations (VGAMs) are rare congenital abnormalities (less than 1/25 000 deliveries), which can cause severe morbidity and mortality, particularly in neonates but also in infants and older children. ${ }^{1-5}$ They present in several different ways in childhood, the most striking being as high output cardiac failure in the newborn period. ${ }^{6}$ In the past, this was usually associated with rapid progression to multisystem organ failure (MOF) and death, despite vigorous treatment and supportive medical care. ${ }^{7}$

In the past decade, endovascular treatment has emerged as the treatment of choice for VGAM presenting in infancy with heart failure. Embolisation, both of feeding arteries and draining veins, can result in considerable reduction in aneurysmal blood flow, and has produced encouraging results in selected infants with VGAM. ${ }^{189}$

To date, however, endovascular treatment has been generally used on a selective basis in infants with VGAM, and in many series, neonates less than 1 month of age have not been treated because of perceived poor outcome. Lasjaunias and ter Brugge $^{10}$ have proposed a scoring system to select those neonates with cardiac failure that may gain most benefit from endovascular treatment. This scoring system is based on an assessment of MOF associated with the high output state. These investigators maintain that VGAM related cardiac failure in the neonatal period with MOF is associated with a high rate of cerebral infarction, and thus poor prognosis for long term neurodevelopmental outcome. ${ }^{11}{ }^{12}$

Modern neonatal intensive care, neuroanaesthesia, and endovascular treatments have the potential to improve survival and minimise subsequent morbidity in this group. Our unit's philosophy is therefore that urgent endovascular and aggressive medical treatment of cardiac failure should be instituted as soon after diagnosis as possible. A review was undertaken of the clinical features, investigations, and medical management of neonates with VGAM related cardiac failure referred to our institution over the past five years. Our purpose was fourfold:

(1) to highlight the important aspects of assessment and stabilisation before embolisation, as well as the medical management during embolisation;

(2) to elucidate the most consistently useful treatments of cardiac failure:

(3) to document the hospital course and complications in neonates with VGAMs;

(4) to review the long term outcome of VGAMs presenting with intractable heart failure in the newborn period, and examine whether the severity of neonatal cardiac failure or the presence of MOF are predictors of neurodevelopmental outcome.

This group has also examined the timing and nature of the embolisation procedures performed in infants with VGAMs over the same time period. This review is the subject of a separate report, which complements the data presented here. ${ }^{13}$

\section{METHODS}

All neonates, treated at the Royal Children's Hospital, Melbourne, with the diagnosis of VGAMs and cardiac failure

Abbreviations: VGAM, vein of Galen aneurysmal malformation; AVM, arteriovenous malformation; MOF, multisystem organ failure; $C T$, computed tomography 
Table 1 Summary of clinical data for nine children treated for vein of Galen aneurysmal malformations (VGAMs) presenting with cardiac failure in neonatal period

\begin{tabular}{|c|c|c|c|c|c|c|}
\hline Patient & Antenatal diagnosis & $\begin{array}{l}\text { Age at } \\
\text { admission } \\
\text { (hours) }\end{array}$ & $\begin{array}{l}\text { Age at } \\
\text { intubation } \\
\text { (hours) }\end{array}$ & $\begin{array}{l}\text { Lactate/base excess } \\
\text { after stabilisation } \\
\text { (mmol/l) }\end{array}$ & $\begin{array}{l}\text { Lasjaunias } \\
\text { score* }^{*}\end{array}$ & $\begin{array}{l}\text { Initial neuroimaging size (AP } \times \\
\text { transverse } \times \text { craniocaudal) }\end{array}$ \\
\hline 1 & No & 8 & 6 & 2.5/BE 10 & 6 & $\begin{array}{l}\text { Brain parenchyma normal (MRI); size of } \\
\text { lesion } 2.9 \times 3.9 \times 2.7 \mathrm{~cm}\end{array}$ \\
\hline 2 & Yes (31 weeks) & 2 & 1 & $3.5 / \mathrm{BE}-5$ & 10 & $\begin{array}{l}\text { Brain parenchyma normal (MRI); size of } \\
\text { lesion } 1.5 \times 1.8 \times 1.9 \mathrm{~cm}\end{array}$ \\
\hline 3 & No & 2 & $5 \mathrm{~min}$ & $9.3 / \mathrm{BE}-12.9$ & 3 & $\begin{array}{l}\text { Brain parenchyma abnormal (US); size of } \\
\text { lesion } 4.4 \times 2.3 \times 2.5 \mathrm{~cm}\end{array}$ \\
\hline 4 & No & 36 & 33 & 10.9/BE -8.4 & 6 & $\begin{array}{l}\text { Brain parenchyma abnormal (US), R } \\
\text { temporal \& occipital lobe increased } \\
\text { echogenicity; size of lesion } 2 \times 1.8 \times 1.6 \\
\mathrm{~cm}\end{array}$ \\
\hline 5 & No & 38 & 35 & $5.7 / \mathrm{BE}-15$ & 5 & $\begin{array}{l}\text { Brain parenchyma normal (MRI); size of } \\
\text { lesion } 2 \times 2 \times 2.5 \mathrm{~cm}\end{array}$ \\
\hline 6 & No & 3 & 2 & $5.8 / \mathrm{BE}-14$ & 7 & $\begin{array}{l}\text { Brain parenchyma normal (MRI); size of } \\
\text { lesion } 1.9 \times 1.5 \times 1.5 \mathrm{~cm}\end{array}$ \\
\hline 7 & Yes (36 weeks) & 5 & $5 \mathrm{~min}$ & $5.3 / \mathrm{BE}-13$ & 4 & $\begin{array}{l}\text { Brain parenchyma normal (fetal MRI,US); } \\
\text { size of lesion } 4 \times 2 \times 3 \mathrm{~cm}\end{array}$ \\
\hline 8 & Yes (38 weeks) & 48 & 28 & 7.2/BE -7.2 & 7 & $\begin{array}{l}\text { Brain parenchyma normal (MRI,US); size } \\
\text { of lesion } 2.5 \times 2.5 \times 2 \mathrm{~cm}\end{array}$ \\
\hline 9 & Yes (32 weeks) & 0.2 & $15 \mathrm{~min}$ & $7.29 / \mathrm{BE}-6$ & 8 & $\begin{array}{l}\text { Brain parenchyma normal (fetal MRI); } \\
\text { size of lesion } 2 \times 1.1 \times 2.8 \mathrm{~cm}\end{array}$ \\
\hline
\end{tabular}

*Neonatal rating score proposed by Lasjaunias and ter Brugge ${ }^{10}$ derived from measures of cardiac, cerebral, hepatic, renal, and respiratory function. A total score of less than 8 results in a decision not to treat; a score of 8-12 prompts emergency endovascular intervention; a score greater than 12 recommends medical treatment alone and delayed embolisation at 5 months of age. $\mathrm{BE}$, Base excess.

over the period 1996-2001 were identified. Only infants with VGAM or dural arteriovenous malformation (AVM) who presented at less than 1 month of age with cardiac failure were included. Each case was managed by at least one of the authors. This series includes two cases in which the diagnosis of VGAM was made before birth.

The case records of each infant were reviewed, and, where necessary, supplemental information was obtained from hospital notes and personal records of the authors. Specific information sought from these sources included:

(a) prenatal and perinatal details;

(b) clinical course from birth, with emphasis on degree of cardiac failure and indicators of MOF;

(c) results of neuroimaging, in particular findings of ultrasound, magnetic resonance imaging, and magnetic resonance angiography studies;

(d) echocardiographic findings, in the initial diagnostic study, after the start of treatment, and in later follow up studies;

(e) results of other cardiac investigations;

(f) treatments used and their effects;

(g) timing and nature of endovascular interventions, and the physiological effects of embolisation;

(h) hospital course and complications;

(I) findings at clinical follow up.

Eight infants were born at other centres and transported to our unit by a specialised neonatal transport service; one was delivered by caesarian section at our institution to minimise the effect of postnatal transport. Before transfer, basic management of severe cardiac failure secondary to VGAM consisted of mechanical ventilation and combination diuretic and inotropic support. A neonatal score, as proposed by Lasjaunias and ter Brugge, ${ }^{10}$ was assigned on the basis of cardiac, respiratory, renal, hepatic, and cerebral dysfunction on arrival in our unit. Abnormal neurological events or seizures that occurred before sedation or neuromuscular blockade were scored appropriately. Seven infants, however, were electively intubated for transfer and were sedated or paralysed until after neurointervention. This prevented full neurological assessment, and these neonates were therefore assigned the highest (best) score in this section. Because the neurological component of the Lasjaunias score was difficult to assess, we also identified other prognostic indicators such as base excess or lactate.

After stabilisation, all infants were assessed by transthoracic Doppler echocardiography with colour flow mapping. One infant also had cardiac catheterisation to exclude hypoplastic left heart syndrome.

Transvenous embolisation through an existing femoral venous catheter or ultrasound guided transtorcular access was the intervention of choice in the first week of life despite the perceived increased risk of intracerebral bleeding, perforation, and morbidity with transvenous access. Transarterial embolisation was the preferred route of treatment for the second and subsequent interventions if cardiac failure persisted for 24-48 hours after the initial intervention.

\section{RESULTS}

\section{Perinatal data}

Table 1 summarises the clinical details of the cases. Mean (SD) gestational age was 39 (1.85) weeks and mean (SD) birth weight was 3382 (308) g. There was no evidence of hypoxaemia or birth asphyxia in seven of the nine infants. One infant (case 1) had an Apgar score of 2 at five minutes, requiring bag and mask ventilation for three minutes. Another (case 3) was flaccid and cyanosed at delivery, requiring intubation. All nine neonates subsequently presented with cardiomegaly, tachycardia, and tachypnoea consistent with high output cardiac failure on day 1. Initial stabilisation for transfer to our unit included elective intubation and ventilation. Two neonates (cases 3 and 4) rapidly progressed to MOF with hepatic dysfunction, disseminated intravascular coagulation, and respiratory failure. Seizures were present at diagnosis in one neonate (case 3), but none presented with intracranial haemorrhage or hydrocephalus. Three of the nine had serum lactate levels of $2.5-5 \mathrm{mmol} / \mathrm{l}$ (associated with $27 \%$ mortality in previous papers), ${ }^{14}$ and six had serum lactate levels greater than $5 \mathrm{mmol} / \mathrm{l}$ (associated with 57\% mortality).

\section{Neuroimaging}

Choroidal VGAMs were diagnosed in eight patients, with one infant (case 6) having a dural AVM with aneurysmal 
Table 2 Cardiovascular variables before intervention, inotropic support required to maintain perfusion, and initial response to interventional embolisation

\begin{tabular}{|c|c|c|c|c|c|}
\hline Patient & ECG & RV pressure (\%)* & $\begin{array}{l}\text { RV fractional } \\
\text { shortening }(\%)\end{array}$ & $\begin{array}{l}\text { Response to initial } \\
\text { embolisation }\end{array}$ & Cardiovascular drugs \\
\hline 1 & Sinus (RVH) & 109 & 26 & $\uparrow$ in MBP by $22 \%$ & Dopamine, frusemide \\
\hline 2 & Sinus & 50 & 42 & $\uparrow$ in SBP by $10 \%$ & Dopamine \\
\hline 3 & $\begin{array}{l}\text { Sinus tachycardia } 200 \\
\text { beats/min, lateral ischaemia }\end{array}$ & 115 & 44 & $\begin{array}{l}\text { Fulminant right heart failure, } \\
\text { asystole }\end{array}$ & $\begin{array}{l}\text { Dopamine, noradrenaline, } \\
\text { nitric oxide }\end{array}$ \\
\hline 4 & Sinus RVH, inferior ischaemia & 115 & 19 & $\uparrow$ in SBP by $50 \%$ & Dopamine, $\mathrm{PGE} 1^{\dagger}, \mathrm{SNP}^{\ddagger}$ \\
\hline 5 & $\begin{array}{l}\text { Sinus tachycardia, } 240 \\
\text { beats/min, RBBB }\end{array}$ & 67 & 39 & $\uparrow$ in SBP by $30 \%$ & $\begin{array}{l}\text { Dopamine, adrenaline, } \\
\text { SNP }^{\ddagger}, \text { GTN }^{\S}\end{array}$ \\
\hline 6 & Sinus RVH and ischaemia & 90 & 39 & $\uparrow$ in SBP by $30 \%$ & Dobutamine, frusemide \\
\hline 7 & $\begin{array}{l}\text { Complete heart block, } 110 \\
\text { beats } / \mathrm{min}\end{array}$ & 118 & 15 & $\uparrow$ in SBP by $15 \%$ & $\begin{array}{l}\text { Dobutamine, SNP }{ }^{\ddagger}, \mathrm{GTN}^{\S} \text {, } \\
\text { nitric oxide }\end{array}$ \\
\hline 8 & Sinus & 65 & 30 & $\uparrow$ in SBP by $15 \%$ & Milrinone \\
\hline 9 & $\begin{array}{l}\text { Sinus tachycardia RVH, lateral } \\
\text { ischaemia }\end{array}$ & 110 & 28 & $\uparrow$ in SBP by $15 \%$ & Milrinone \\
\hline
\end{tabular}

*Expressed as percentage of measured systemic arterial or aortic pressure.

ECG, Electrocardiogram; RVH, right ventricular hypertrophy; RBBB, right bundle branch block; RV, right ventricular; $M B P$, mean arterial blood pressure SBP, systolic blood pressure; PGE I, prostaglandin E I; SNP, sodium nitroprusside; GTN, glyceryl trinitrate.

dilatation of the vein of Galen. Transcranial ultrasound with colour Doppler was used to quantify flow velocity and size of the aneurysm and to provide a baseline for subsequent follow up. Magnetic resonance imaging to exclude pre-existing cerebral injury and to characterise the anatomy was performed on day 1 unless fetal magnetic resonance imaging had been performed. Brain parenchyma was normal before intervention in seven of the nine neonates (table 1). All VGAMs were classified as choroidal or Yasargil type $3,{ }^{15}$ as would be expected in perinatal presentation with cardiac symptoms.

\section{Echocardiography}

Transthoracic echocardiography showed right ventricular enlargement with tricuspid insufficiency and raised pulmonary arterial pressure and normal left ventricular function in seven of the nine neonates. Reversal of flow during diastole was shown in the proximal descending thoracic aorta in seven of the nine cases. A patent ductus arteriosus with right to left shunting was present in seven cases. Suprasystemic pulmonary arterial pressure (calculated from tricuspid regurgitant jet) was present in five of the nine neonates. One neonate (case 4) also had cardiac catheterisation to exclude hypoplastic left heart syndrome before diagnosis of VGAM. In this case, right atrial and left and right ventricular end diastolic pressures were considerably raised. Right ventricular and pulmonary arterial pressures were suprasystemic compared with the measured left ventricular pressures. One infant has partial anomalous pulmonary venous drainage to the superior vena cava (sinus venosus), which has not yet been corrected.

\section{Electrocardiography}

Evidence of right ventricular hypertrophy was seen in six of the nine patients and combined ventricular hypertrophy in two patients (table 2). Five of nine patients had unequivocal evidence of myocardial ischaemia before embolisation. ${ }^{16}$ One infant (case 7) developed complete heart block (with a heart rate of 80 beats/min) during embolisation requiring emergency epicardial pacing.

\section{Treatment of cardiac failure}

Five of the nine neonates were initially stabilised with dopamine infusions and two with dobutamine infusions (table 2). One patient (case 5) developed supraventricular tachycardia to a rate of 240 beats/min, necessitating cessation of high dose dopamine and adrenaline infusions. Systemic perfusion in this case abruptly improved in response to low dose dopamine in combination with sodium nitroprusside. From case 3 onwards, cardiac failure unresponsive to dopamine or dobutamine (up to a dose of $10 \mu \mathrm{g} / \mathrm{kg} / \mathrm{min}$ ) was treated with a combination of $\beta$ adrenergic agonists and a vasodilator. The inotrope of choice was dopamine with either sodium nitroprusside (1-5 $\mu \mathrm{g} / \mathrm{kg} / \mathrm{min}$ ) or glyceryl trinitrate ( $1-5 \mu \mathrm{g} / \mathrm{kg} / \mathrm{min})$. In three cases, direct acting arterial vasodilators in combination with $\beta$ adrenergic agents yielded the most sustained improvement in systemic perfusion. In the final two patients in the series (cases 8 and 9), cardiac failure was treated solely with a phosphodiesterase inhibitor (milrinone $0.4-0.75 \mu \mathrm{g} / \mathrm{kg} / \mathrm{min}$ ).

The response to medical treatment was assessed by serial transthoracic echocardiography. Improved systemic perfusion was shown by increases in forward flow relative to reverse flow in the descending aorta and reduction in right to left ductal shunting. Inhaled nitric oxide was used in two neonates with severe pulmonary arterial hypertension but with limited effect on measured and calculated pulmonary arterial pressures.

All patients undergoing endovascular treatment in the first week of life were treated because of worsening cardiac failure despite maximal medical treatment. In unstable neonates transvenous embolisation using a femoral or ultrasound guided transtorcular approach was the primary intervention. This occurred between days 1 and 4 in the eight cases of refractory cardiac failure ( 12 procedures within first week of life, median age at first procedure 3 days). The only patient with cardiac failure not treated with endovascular treatment in the first week was managed medically until 6 months of age, when a series of three transarterial treatments were performed. This patient had severe stenosis of the main venous outflow from the VGAM, which would have decreased blood flow across the aneurysm and thus reduced the high output cardiac failure.

\section{Hospital course}

Of the eight patients treated in the first week of life for intractable cardiac failure, one was well controlled with the first treatment, one died during the initial treatment, and staged embolisation was required in six others at one, three, and four days after the initial treatment (table 3 ). The five surviving neonates with cardiac failure required repeat endovascular treatment to treat recurrent cardiac or respiratory failure. Presentation was either failure to wean from mechanical ventilation or respiratory failure after extubation. Eight neonates with severe cardiac failure showed an immediate increase in systemic systolic and mean arterial blood pressure of 30-50\% after coiling, but this was not maintained (table 2). Clinically the hyperdynamic circulation persisted for a significant length of time despite reduction in AVM flow.

\section{Outcome}

One neonate in intractable cardiac failure (case 3) developed MOF with cardiac failure, respiratory failure, renal and 
Table 3 Clinical outcome including magnetic resonance angiography/magnetic resonance imaging demonstration of residual shunt, neurological development, and number of procedures performed in the first year of life

\begin{tabular}{|c|c|c|c|c|c|c|}
\hline Patient & $\begin{array}{l}\text { Timing and nature of } \\
\text { intervention }\end{array}$ & $\begin{array}{l}\text { Duration of } \\
\text { ventilation } \\
\text { (days)* }^{*}\end{array}$ & $\begin{array}{l}\text { Length of } \\
\text { hospital stay } \\
\text { (days) }\end{array}$ & $\begin{array}{l}\text { Age at latest } \\
\text { follow up } \\
\text { (months) }\end{array}$ & Clinical findings & Follow up neuroradiology \\
\hline 1 & $\begin{array}{l}\text { TV }(2 \text { days), } \Pi T(6 \text { days }), \\
\text { TA ( } 39 \text { days) }\end{array}$ & $\begin{array}{l}15 \\
\text { (25 CPAP) }\end{array}$ & 51 & 45 & $\begin{array}{l}\text { Age appropriate } \\
\text { development }\end{array}$ & Normal CT MRI at 12 months \\
\hline 2 & $\begin{array}{l}\text { TA (6 months), TA } 7 \\
\text { months), TA (7 months) }\end{array}$ & 1 & 8 & 40 & $\begin{array}{l}\text { Age appropriate } \\
\text { development }\end{array}$ & CT scan normal at 22 months \\
\hline 3 & $\Pi$ ( 2 days $)$ & 1 & 1 & 0 & Died at day 2 & Died \\
\hline 4 & $\begin{array}{l}\text { TV ( } 3 \text { days), TA (13 } \\
\text { months), TA } 20 \text { months), } \\
\text { TA } 22 \text { months) }\end{array}$ & 15 & 32 & 36 & $\begin{array}{l}\text { Moderate developmental } \\
\text { delay }\end{array}$ & $\begin{array}{l}\text { CT scan at } 17 \text { months: small R } \\
\text { parietotemporal infarct }\end{array}$ \\
\hline 5 & $\begin{array}{l}\text { TV }(4 \text { days), TA (7 days), } \\
\text { TV (13 days), TA (12 } \\
\text { months) }\end{array}$ & 14 & 32 & 24 & $\begin{array}{l}\text { Age appropriate } \\
\text { development }\end{array}$ & $\begin{array}{l}\text { CT scan normal at } 12 \text { months; } \\
\text { complete obliteration AVM }\end{array}$ \\
\hline 6 & $\begin{array}{l}T \mathrm{~V}+\mathrm{TA} \\
\text { (6 days) }\end{array}$ & 5 & 20 & 48 & $\begin{array}{l}\text { Age appropriate } \\
\text { development }\end{array}$ & CT scan normal at 24 months \\
\hline 7 & $\begin{array}{l}\text { TV }(1 \text { day), TV }(2 \text { days }), \\
\text { TV }+\pi \text { ( } 11 \text { days })\end{array}$ & 26 & 26 & 0 & Died at day 24 & $\begin{array}{l}\text { CT scan at day 17: diffuse } \\
\text { anoxic brain injury }\end{array}$ \\
\hline 8 & $\begin{array}{l}\text { TV }(2 \text { days), TA ( } 6 \text { days), } \\
\text { TA ( } 22 \text { days) }\end{array}$ & 7 & 29 days & 10 & $\begin{array}{l}\text { Age appropriate } \\
\text { development }\end{array}$ & MRI normal at 8 months \\
\hline 9 & $\begin{array}{l}\text { TV }(1 \text { day), TA ( } 3 \text { days), } \\
\text { TA (8 days), TA ( } 14 \text { days) }\end{array}$ & 14 & 39 days & 1 & Died & $\begin{array}{l}\text { Severe ischaemic cortical } \\
\text { injury }\end{array}$ \\
\hline
\end{tabular}

hepatic dysfunction, and coagulopathy. She failed to respond to infusion of adrenaline (epinephrine) or noradrenaline (norepinephrine). Progressive failure to oxygenate in the presence of suprasystemic pulmonary arterial pressures was not reversed by nitric oxide (NO) to a maximum of $80 \mathrm{ppm}$. Emergency transvenous embolisation was complicated by severe unresponsive right heart failure and asystolic cardiac arrest during the procedure. In one other infant who died, treatment was discontinued at day 24 after computed tomography (CT) showed diffuse hypoxic-ischaemic cerebral injury and cortical laminar necrosis. This injury may have occurred during a pulmonary hypertensive crisis before the first endovascular treatment. One neonate developed extensive progressive encephaloleucomalacia after the fourth endovascular treatment consistent with cerebral ischaemia. This occurred despite resolution of cardiac failure and reduction in aneurysmal flow, suggesting a continuing steal phenomenon. Onset of sustained uncontrolled epilepsy led to withdrawal of treatment. Two of the neonates who died had transtorcular approaches to the VGAM.

Five patients have no evidence of developmental delay or heart failure, and one awaits delayed clinical assessment. Mild developmental delay is present in the other survivor (case 4) at 36 months of age (table 3 ). Imaging showed significant enlargement of cerebrospinal fluid spaces, parenchymal calcifications, and hypodensity consistent with venous hypertension and ischaemia. A ventriculoperitoneal shunt was performed for persistent hydrocephalus followed by surgical clipping of the remaining anterior cerebral artery supply.

Final angiograms showed complete (three) or near complete (three) angiographic obliteration in the six survivors. Follow up CT scans at 12-24 months were normal in five of the six survivors. The child with mild developmental delay has a small right temporoparietal infarct on CT scan.

Our policy on follow up imaging of these patients depends on the degree of occlusion achieved at embolisation. After discharge, infants are followed at three monthly intervals by the treating neonatologists until 12 months of age. Endovascular treatment sessions are arranged every three to six months depending on the clinical status and response to prior embolisation. At 6 months of age, follow up angiography is performed. If persistent high flow through the AVM is found, repeat transarterial embolisation is performed at the same session. A repeat angiogram at 12 months is indicated if less than complete occlusion is achieved at the six month angiogram. ${ }^{13}$

\section{DISCUSSION}

Without interventional neuroradiology and embolisation, the prognosis is poor for neonates whose primary presentation is early severe cardiac failure secondary to VGAM. Severe heart failure rapidly progresses to MOF and death. ${ }^{17}$ It has been suggested that VGAM related cardiac failure presenting in the neonatal period with MOF is associated with a high rate of cerebral infarction and thus poor prognosis for long term neurodevelopmental outcome. ${ }^{11}{ }^{12}$ On this basis, endovascular treatment has been withheld in such babies. In this series, intervention was not withheld in neonates solely on the basis of severe cardiac failure. In our opinion, unless the excess flow through the AVM is reduced by early neurointervention and aggressive management of cardiac failure, severe cerebral injury occurs.

This cohort of patients had significant risk of mortality associated with the VGAM. If assessed by Lasjaunias scores, only one neonate in this series would have been offered neurointervention before 5 months of age. Despite this, our results (five without neurological impairment, one moderate impairment, and three deaths) are similar to recent series, ${ }^{141819}$ in which selected neonates were treated after medical stabilisation for up to three months before the first intervention. The improved survival reported here may be due to our aggressive approach to early endovascular intervention as well as the management of cardiac failure used.

Cardiac failure associated with VGAM is unique. In utero cardiac failure secondary to VGAM is rare ${ }^{20}{ }^{21}$ because the low resistance of the cerebral AVM is balanced by the low resistance uteroplacental unit, allowing perfusion of the peripheries. With loss of the placenta at birth, up to $70 \%$ of cardiac output is directed to the cerebral circulation. Pulmonary arterial pressures remain raised, and the ductus arteriosus remains open, directing right ventricular output through the patent ductus arteriosus and into the descending aorta. ${ }^{62}$ The right ventricle becomes distended and noncompliant because of the chronic pressure load. Subsequent right to left shunting at atrial and ductal levels causes arterial hypoxaemia and increases the likelihood of ventricular failure. The left ventricle is hyperkinetic with a shortening fraction 
greater than $40 \%$. Biventricular failure may coexist with a supranormal shortening fraction. A normal shortening fraction therefore represents severe biventricular failure. ${ }^{10}$

A large shunt through the VGAM occurs during diastole. This is suggested by diastolic retrograde filling of carotid arteries and reversal of flow in the descending aorta (steal phenomenon) at catheterisation, as well as differences in inferior and superior caval oxygen saturations. ${ }^{22-24}$ The increased diastolic flow to the VGAM reduces coronary blood flow and, in combination with increased ventricular pressure, reduces subendocardial perfusion. This may produce myocardial ischaemia and potentially exacerbate right heart failure. Right ventricular pressure loading and ventricular septal interaction lead to low normal cardiac output. ${ }^{22} 25$

Severe heart failure associated with VGAM appears to be more severe than heart failure associated with intracardiac anomalies that place a volume load on the right ventricle. It has been suggested that this is because the volume load is obligatory and continues despite increases in pulmonary artery resistance. ${ }^{16}$ As a result, stabilisation of neonates before neurointervention or neurosurgery is difficult and the cardiac failure is often resistant to treatment.

The use of $\beta$ adrenergic agents (dobutamine, dopamine, or adrenaline) in this setting often worsens cardiac output. ${ }^{68}$ Improvements in contractility are not substantial because of the right ventricular dilatation and ventricular septal interdependence. Shortening of diastolic coronary filling time induced by tachycardia also worsens diastolic dysfunction. Elecrtocardiographic findings of myocardial ischaemia and pathological findings of subendocardial ischaemia suggest that subendocardial ischaemia contributes to the deterioration of ventricular function. ${ }^{16}$ In our series, high dose $\beta$ agonists were associated with significant adverse physiological events (including extreme tachyarrhythmias and transient ST-T wave changes consistent with ischaemia) and clinical deterioration. In contrast, low dose dopamine in combination with vasodilator treatment produced considerable improvement in systemic perfusion and reduction in metabolic acidosis.

The use of systemic arterial vasodilators or phosphodiesterase inhibitors has not previously been reported in neonates with VGAM who fail to respond to conventional inotropic support. Their use was based on the pathophysiology of an extracardiac, intracranial, low resistance circuit. Although total systemic vascular resistance is reduced with intracranial AVMs, extracranial systemic vascular resistance is raised. ${ }^{22} 26$ Any intervention that reduces the extracranial systemic vascular resistance is likely to improve systemic perfusion and acidosis. ${ }^{27} \mathrm{~A}$ case report of two neonates with severe cardiac failure secondary to VGAM receiving prostaglandin El supports this theory, as they sustained temporary increases in oxygenation and systemic perfusion. ${ }^{26}$

Short term treatment with milrinone has not been reported in vein of Galen or other extracardiac AVMs, but phosphodiesterase inhibitors have been shown to improve indices of cardiac output in low cardiac output states after cardiac surgery. In the critically ill, milrinone improves systolic and diastolic function, produces systemic and pulmonary vasodilatation, and matches coronary arterial supply and demand. ${ }^{28}$ Nitroprusside and nitroglycerine also improve systemic output by decreasing systemic vascular resistance in an analogous way to the effect of a low resistance placental bed. ${ }^{29}$ In contrast, the two neonates in our series with the most severe cardiac failure did not respond to inhaled nitric oxide alone, as would be expected with persistent pulmonary hypertension. ${ }^{8}$

The excessive cerebral blood flow in VGAMs adversely affects neurological outcome in a number of ways. ${ }^{49}{ }^{30}$ Raised cerebral venous pressure adversely affects regional cerebral blood flow, whereas periventricular leucomalacia is a result of a watershed phenomenon secondary to intracerebral arterial steal. Arterial vasodilators (especially nitroprusside, glyceryl trinitrate, and milrinone) used to treat severe cardiac failure have a role in reducing neurological injury before, during, and after surgery. ${ }^{31}$ They play a significant role in stabilisation before intervention. During surgery, they offset rapid changes in systemic vascular resistance induced by coil occlusion of feeding vessels of the AVM..$^{32}$ Both ischaemia/reperfusion vascular injury and transmission of abrupt changes in perfusion through a pressure passive circulation are important in pathogenesis of germinal matrix haemorrhage. ${ }^{33}$ After surgery, they may reduce the incidence of cerebral hyperaemia secondary to normal pressure breakthrough syndrome. ${ }^{19}$ Prevention of hypertension during and after AVM embolisation also theoretically reduces the incidence of AVM nidus rupture secondary to increased intravascular pressure proximal to the site of occlusion or rerouting of blood flow and pressure away from the AVM. ${ }^{34} 35$

\section{Conclusion}

Severe neonatal cardiac failure secondary to VGAM is not an absolute contraindication to interventional neuroradiology provided that expert neonatal intensive care, anaesthesia, and interventional neuroradiology are available. It is our opinion that reproducing the balance of systemic vasodilatation seen in fetal life by appropriate low dose inotropic support and peripheral vasodilatation improves cardiac output. Phosphodiesterase inhibitors such as milrinone may be ideal for treatment of cardiac failure in patients with VGAM, especially those with reversal of flow in the descending aorta. Rapid progression to MOF despite aggressive medical treatment continues to be a contraindication to intervention because of poor neurological outcome.

\section{Authors' affiliations}

G P Frawley, P A Dargaville, P J Mitchell, B M Tress, P Loughnan, Department of Anaesthesia, Royal Children's Hospital, Parkville, Victoria 3052, NSW, Australia

\section{REFERENCES}

1 Lasiaunias $\mathbf{P}$, Hui $F$, Zerah M. Cerebral arteriovenous malformations in children. Management of 179 consecutive cases and review of the literature. Childs Nerv Syst 1995;11:66-79.

2 Halbach VV, Dowd CF, Higashida RT, et al. Endovascular treatment of mural type vein of Galen malformations. J Neurosurg 1998;89:74-80.

3 Allison JW, Davis P, Sato Y, et al. Intracranial aneurysms in infants and children. Pediatr Radiol 1998;28:223-9.

4 Ciricillo SF, Edwards MS, Schmidt KG. Interventional neuroradiological management of vein of Galen malformation of the neonate. Neurosurgery 1990;27:22-7.

5 Menovsky T, van Overbeeke JJ. Cerebral arteriovenous malformations in childhood: state of the art with special reference to treatment. Eur J Pediatr 1997; 156:741-6.

6 Garcia-Monaco R, De Victor D, Mann C, et al. Congestive cardiac manifestations from cerebrocranial arteriovenous shunts. Endovascula management in 30 children. Childs Nerv Syst 1991;7:48-52.

7 Yamashita Y, Abe T, Ohara N. Successful treatment of neonatal aneurysmal dilatation of the vein of Galen: the role of prenatal diagnosis and trans-arterial embolization. Neuroradiology 1992;34:457-9.

8 Bouvaist H, Rossignol AM, Rocca C, et al. Aneurysm of the vein of Galen and cardiac insufficiency. Current therapeutic approach. Arch Mal Coeur Vaiss 1998:91:637-43.

9 Borthne A, Carteret M, Baraton J, et al. Vein of Galen vascular malformations in infants: clinical radiological and therapeutic aspects. Eur Radiol 1997; 7:1252-8.

10 Lasjaunias $\mathbf{P}$, ter Brugge K. Vein of Galen aneurysmal malformation. In: Lasjaunias $\mathrm{P}$, ed. Vascular disease in neonates, infants and children. Berlin: Springer-Verlag, 1997:67-136.

11 Nelson M, Dickinson DF, Wilson N. Transtorcular coil embolization of malformations of the vein of Galen: rapid resolution of heart failure in neonates. Int J Cardiol 1988;18:437-41.

12 Watson DG, Smith RR, Brann AW. Arteriovenous malformation of the vein of Galen: treatment in a neonate. American Journal of Diseases in Children 1976;130:520-5.

13 Mitchell PJ, Rosenfeld JV, Dargaville P, et al. Endovascular managemen of vein of Galen malformations presenting in the neonatal period. AJNR Am J Neuroradiol 2001;22:1403-9.

14 Deshpande SA, Ward Platt MP. Association between blood lactate and acid base status and mortality in ventilated babies. Arch Dis Child Fetal Neonatal Ed 1997;76:F15-20.

15 Yasargil MG, Antic J, Laciga R, et al. Arteriovenous malformations of vein of Galen: microsurgical treatment. Surg Neurol 1976;3:195-200. 
16 Jedeikin $\mathbf{R}$, Rowe $\mathrm{R}$, Freedom $\mathrm{R}$, et al. Cerebral arteriovenous malformation in neonates. Pediatr Cardiol 1983;4:29-35.

17 Rodesch G, Hui F, Alvarez H, et al. Prognosis of antenatally diagnosed vein of Galen aneurysmal malformations. Childs Nerv Syst 1994:10:79-83

18 Lasjaunias P, Rodesch G, Pruvost P, et al. Treatment of vein of Galen aneurysmal malformation. J Neurosurg 1989;70:746-50.

19 Morgan M, Johnston I, Sundt T, Jr. Normal pressure breakthrough complicating surgery for the vein of Galen malformation: report of three cases. Neurosurgery 1989;24:406-10.

20 Chisholm CA, Kuller JA, Katz VL, et al. Aneurysm of the vein of Galen: prenatal diagnosis and perinatal management. Am J Perinatol $1996 ; 13: 503-6$

21 Lee TH, Shih JC, Peng SS, et al. Prenatal depiction of angioarchitecture of an aneurysm of the vein of Galen with three dimensional color power angiography. Ultrasound Obstet Gynecol 2000;15:337-40.

22 Cummings GC. Circulation in neonates with intracranial arteriovenous fistula and cardiac failure. Am J Cardiol 1980;45:1019-24.

23 Grossman R, Bruce D, Zimmerman RA, et al. Vascular steal associated with vein of Galen aneurysm. Neuroradiology 1984;26:381-6.

24 Saliba E, Santini JJ, Chantepie A. Cardiac and cerebral involvement in aneurysms of the ampulla of Galen. Contribution of echocardiography and cerebral Doppler flowmeter in the neonatal period. Neurochirgurie 1987;33:296-301

25 Patton DJ, Fouron J-C. Cerebral arteriovenous malformation: prenatal and postnatal central blood flow dynamics. Pediatr Cardiol 1995; 16:141-4

26 Covert RF. Response to prostaglandin E 1 in neonates with intracranial arteriovenous malformation treated for suspected congenital heart disease. Pediatr Cardiol 1994;15:81-4.
27 De Victor D, Le Pommelet C. Medical treatment of congestive cardiac failure from cerebral arteriovenous fistulas at Bicetre Hospital. Interventional Neuroradiology 1996;2:49-52.

28 Davies AR, Auzinger GA, Anderson MB. Milrinone in the critically ill. Critical Care and Shock 2000;1:21-34

29 Tamura K, Kawano T. Effects of intravenous nitroglycerin on hemodynamics in neonates with refractory congestive heart failure or PFC. Acta Paediatr Jpn 1990;32:291-8.

30 McConnell ME, Aronin P, Vitek J J. Congestive heart failure in neonates due to intracranial arteriovenous malformation: endovascular treatment. Pediatr Cardiol 1993;14:102-6.

31 Kleindienst A, Hildebrandt G, Glug N, et al. Management of vein of Galen malformations. A review based on five neurosurgically treated cases and literature reports. Zentralb/ Neurochir 1999;60:172-82.

32 Jungreis CA, Horton JA, Hecht ST. Blood pressure changes in feeders to cerebral arteriovenous malformations during therapeutic embolization. ANNR Am J Neuroradiol 1989;10:575-7.

33 Wyatt J, Meek J. Commentary on cerebral intravascular oxygenation correlates with mean arterial pressure in critically ill premature infants. Pediatrics 2000;106:828

34 Massoud T, Hademenos G, Young WL, et al. Can induction of systemic hypotension prevent nidus rupture complicating arteriovenous malformation embolization? Analysis of underlying mechanisms achieved using a theoretical model. ANNR Am J Neuroradiol 2000:21:1255-67.

35 Charafeddine L, Namaguchi Y, Sinkin RA. Disseminated coagulopathy associated with transtorcular embolization of vein of Galen aneurysm in a neonate. J Perinatol 1999;19:61-3.

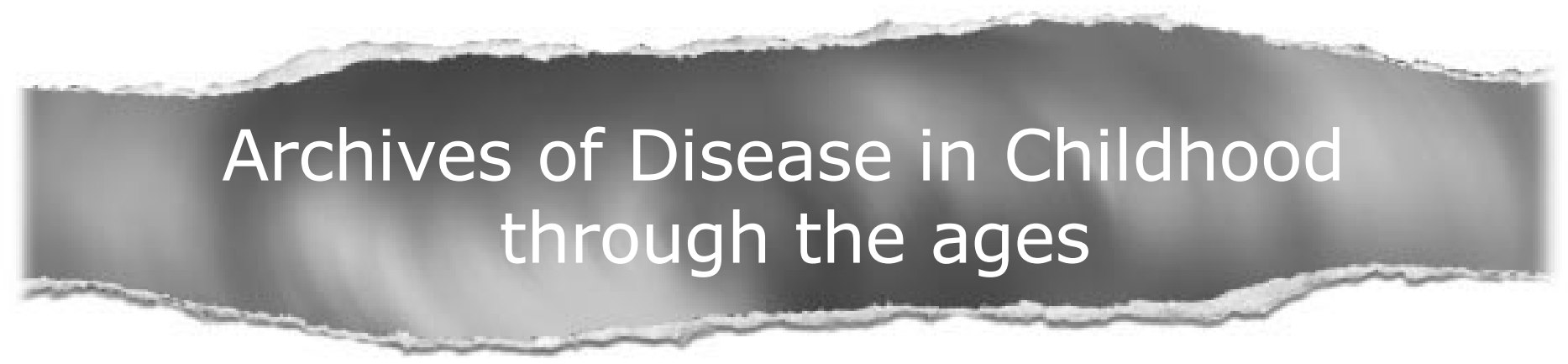

\section{Browse the Archive}

Archives of Disease in Childhood online has an archive of content dating back to 1973. Full text from 1997; abstracts from 1975; table of contents from 1973

\section{www.archdischild.com}

